\title{
Secondary glaucoma following carotid cavernous fistula
}

\section{Glaucoma secundário a fístula carótido-cavernosa}

Rafael Aguiar Carvalho1', Henrique Silva Delloiagono', Alessandro Adad Jammal', Graziela Massa Resende², Hélia Soares Angotti ${ }^{3}$

\begin{abstract}
Carotid-cavernous fistulas are a major cause of secondary glaucoma due to increased episcleral venous pressure. We present the case of a 72-year-old female patient, treated at the Hospital de Clinicas at the Universidade Federal do Triângulo Mineiro (HC-UFTM), with pain, proptosis, episcleral engorgement, chemosis and pulsation in the right eye, with increased intraocular pressure (IOP) on anti-glaucomatous medication. Arteriography showed dural fistula to the right cavernous sinus, with reflux to orbital veins. Treatment with liquid embolization agent was performed, following full recovery of proptosis and congestion of the episcleral vessels. However, the patient maintained increased IOP because of narrow-angle glaucoma development due to the presence of goniosynechiae in $270^{\circ}$, which was controlled satisfactorily with medication.
\end{abstract}

Keywords: Glaucoma/etiology; Carotid-cavernous fistula/complications; Venous pressure; Embolization; Arteriography; Case reports

\section{RESUMO}

As fístulas carótido-cavernosas são uma causa rara, porém grave, de glaucoma secundário por aumento da pressão venosa episcleral. Apresenta-se um caso de uma mulher de 72 anos, negra, atendida no Hospital de Clínicas da Universidade Federal do Triângulo Mineiro (HC-UFTM) com dor, sensação de pulsação, proptose, engurgitamento episcleral e quemose em olho direito, com aumento da pressão intraocular (PIO) apesar do uso de mediação anti-glaucomatosa. Na arteriografia foi evidenciada fístula dural para o seio cavernoso à direita, com refluxo para as veias orbitárias ipsilaterais. Realizou-se tratamento com agente líquido de embolização e, após o tratamento cirúrgico, apresentou melhora completa da proptose e congestão dos vasos episclerais, porém manteve PIO aumentada e desenvolvimento de glaucoma de ângulo fechado pela presença de goniossinéquias em $270^{\circ}$, com controle satisfatório com medicação.

Descritores: Glaucoma/etiologia; Fístula carótidocavernosa/complicações; Pressão venosa; Embolização; Arteriografia; Relatos de casos

\footnotetext{
${ }^{1}$ Residence Program in Ophthalmology, Universidade Federal do Triângulo Mineiro, Uberaba, MG, Brazil.

2 Glaucoma Department, Universidade Federal do Triângulo Mineiro, Uberaba, MG, Brazil.

${ }^{3}$ Discipline of Ophthalmology, Universidade Federal do Triângulo Mineiro, Uberaba, MG, Brazil.

Department of Ophthalmology, Hospital de Clínicas da Universidade Federal do Triângulo Mineiro, Uberaba, MG, Brazil.

The authors declare no conflicts of interests.

Received for publication 21/01/2015 - Accepted for publication 24/05/2015
} 


\section{INTRODUCTION}

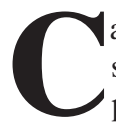

arotid cavernous fistulas are a rare, but serious cause of secondary glaucoma by increasing the episcleral venous pressure. It can be traumatic or spontaneous ${ }^{(1-5)}$. The latter is more frequent in middle-aged or older women with no history of trauma. In these cases, a small fistula is fed by a meningeal branch of the intracavernous internal carotid artery or the external carotid artery, which drains directly into the cavernous sinus or adjacent dural vein ${ }^{(5,6)}$. The mixing of arterial and venous blood leads to a reduction in the blood pressure and increase in the orbital venous pressure, which increases the episcleral venous pressure ${ }^{(5)}$. Patients may present engorged episcleral and conjunctival veins, minimal proptosis and presence of pulse or puff ${ }^{(8)}$. Most patients present high intraocular pressure $(\mathrm{IOP})^{(5,7,9)}$.

\section{Case Report}

T.G.S., 72 years old, black, female, was admitted at the emergency of Hospital das Clínicas da Universidade Federal do Triângulo Mineiro (HC-UFTM) with a conjunctival hyperemia condition, chemosis, pain and sensation of pulse in right eye for 3 months. She was using Glalfital ${ }^{\circledR}$ (dorzolamide hydrochloride $20 \mathrm{~m} / \mathrm{ml}$ and timolol maleate $5 \mathrm{mg} / \mathrm{ml}$, Teuto Brasileiro SA, Brazil) and Glaub ${ }^{\circledR}$ (brimonidine tartrate $2 \mathrm{mg} / \mathrm{ml}$, União Química Farmacêutica Nacional S.A., Brazil) twice a day in the same eye.

Ophthalmological exam: Uncorrected visual acuity: 20/100 in the right eye (RE) and 20/40 in the left eye (LE), proptosis and episcleral engorgement in the RE (Figures 1 and 2), as well as incipient corticonuclear cataracts in both eyes (BE). Intraocular pressure (IOP) of $21 \mathrm{mmHg}$ in the RE and $10 \mathrm{mmHg}$ in the LE measured by Goldmann applanation tonometry (AT900, Haag Streit AG, Switzerland). The funduscopic exam showed tortuosity and engorgement of blood vessels, in addition to points of bleeding in the superior temporal arch. She presented excavation/ disk ratio $(\mathrm{L} / \mathrm{R})$ of 0.7 in BE. Previous ophthalmological exam conducted in 2004 showed IOP of $14 \mathrm{mmHg}$ in the RE and 13 $\mathrm{mmHg}$ in $\mathrm{LE}$, with $\mathrm{L} / \mathrm{R}$ ratio of 0.6 in $\mathrm{BE}$.

The magnetic resonance imaging (MRI) of the head showed: proptosis grade III in the RE, hypertrophy of muscle bellies and hyperintense in $\mathrm{T} 2$ of the extrinsic muscles, dilated superior and inferior right ophthalmic veins. The fistula was not displayed at angioresonance. Arteriography showed dural fistula into the cavernous sinus on the right, with reflux into the ipsilateral orbital veins (Figure 3). The case was then referred to the Neurosurgery sector, in which the treatment was with liquid embolic agent. After confirming dural fistula into the right cavernous sinus with reflux into the superior and inferior orbital veins, a microcatheterization with the artery of the round foramen was made. Then Onyx ${ }^{\circledR}$ (EVOH copolymer, Micro Therapeutics Inc, USA) was injected by microcatheter and filled all fistular points, including those from the inferolateral and meningohypophyseal trunks of the left internal carotid artery. The fistula drainage compartment in the right cavernous sinus and the superior and inferior orbital veins were also duly preeenchidos. The final bilateral control showed dural fistula occlusion with preservation of surrounding blood flow.

After surgery, the patient had complete improvement of proptosis and congestion of the episcleral veins, but kept the

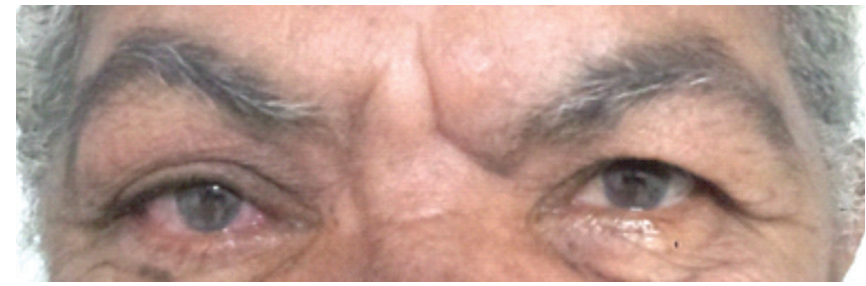

Figure 1: Episcleral engorgement in the RE.

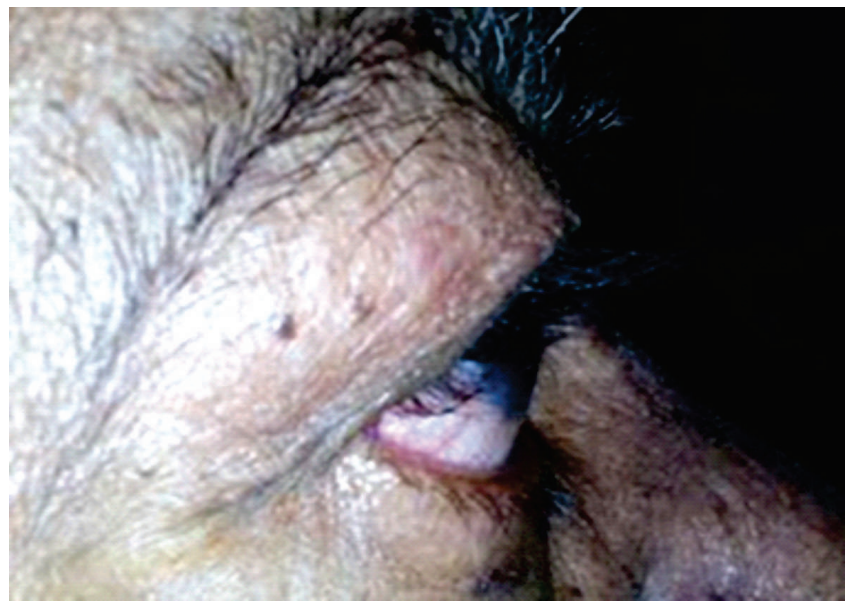

Figure 2: Proptosis and episcleral engorgement in the RE

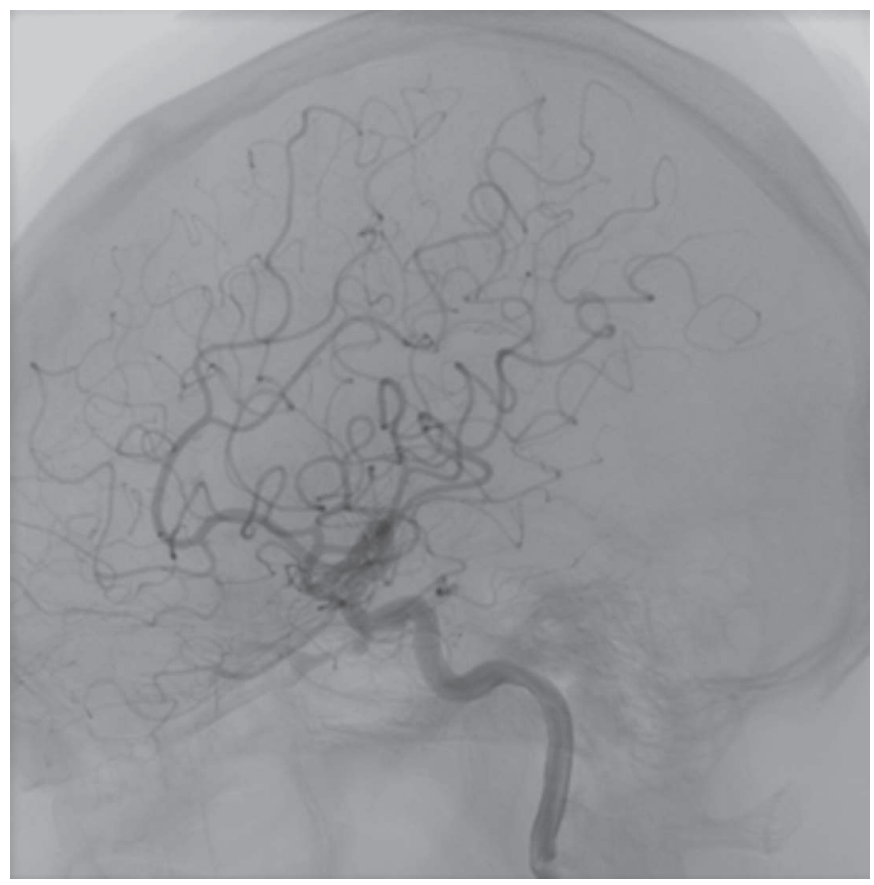

Figure 3: Arteriography. Dural fistula observed into the cavernous sinus on the right, with reflux into the ipsilateral orbital veins (arrow).

IOP without antiglaucoma medication of $21 \mathrm{mmHg}$ in the RE and $14 \mathrm{mmHg}$ in the LE. The treatment restarted with topic timolol maleate $0.5 \%$ and dorzolamide $2 \%$. Patient lost ambulatory follow-up and returned after a year in use of only timolol maleate $0.5 \%$, with IOP of $23 \mathrm{mmHg}$ in the RE and 13 
$\mathrm{mmHg}$ in the LE, $\mathrm{L} / \mathrm{R} 0.8$ with lower tapering and 0.7 in the right and left eyes, respectively. Gonioscopy showed goniosynechia 270 degrees, preserving open angle only in the inferior region. She showed superior arcuate scotoma in the RE to the visual

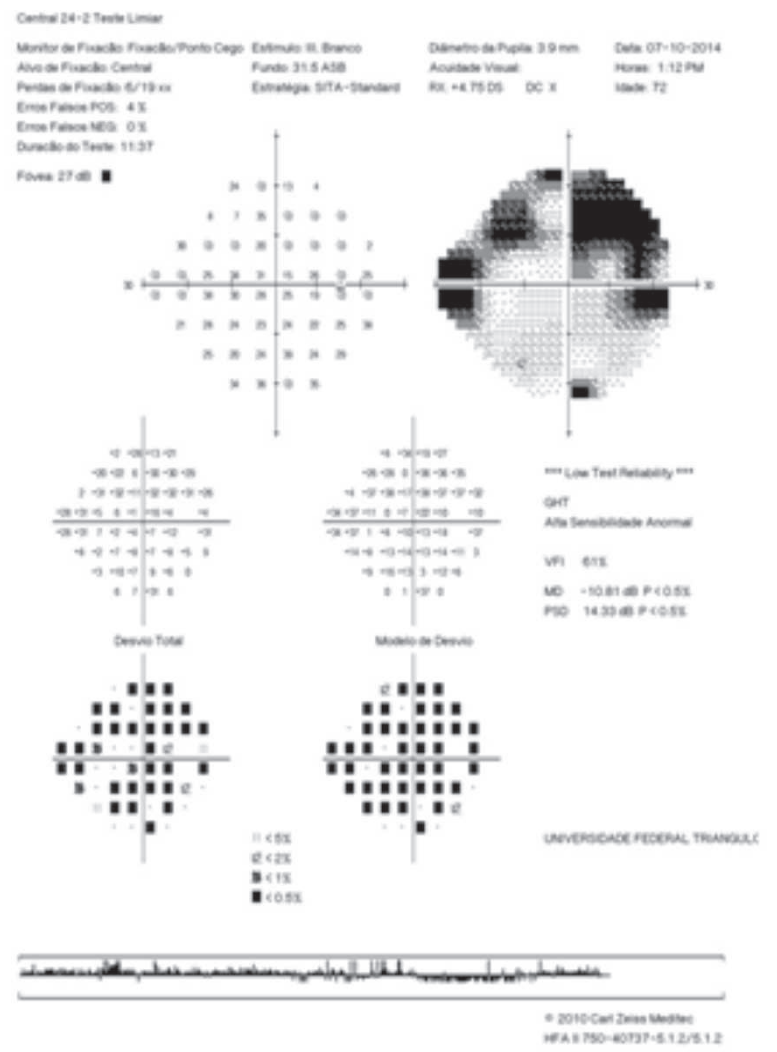

field, but the test was unreliable because of the difficulty in understanding of the patient, being repeated and presenting similar results (Figure 4). Dorzolamide $2 \%$ was added to the treatment regimen, giving satisfactory IOP control.

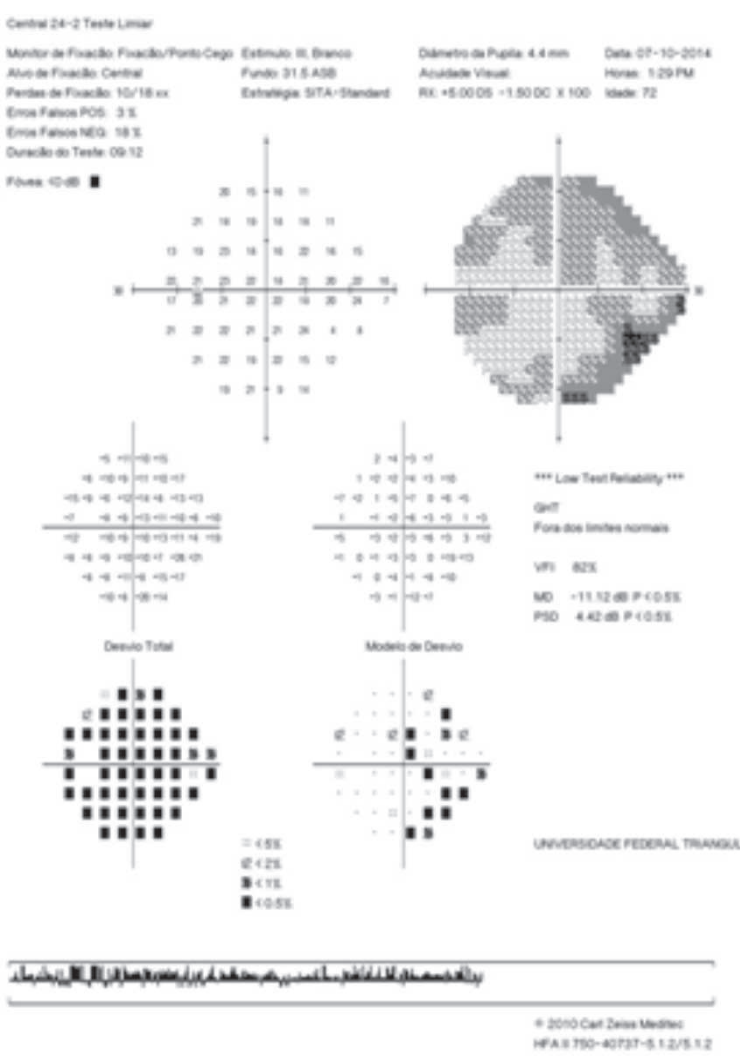

Figure 4: Visual field. 24-2. SITA strategy. Humphrey HFA-II (Carl Zeiss Meditec, Dublin, CA, USA)

\section{DISCUSSION}

Carotid cavernous fistula are a rare cause of secondary glaucoma, and refer to a small vascular communication fed by a meningeal branch of the intracavernous internal carotid artery or the external carotid artery which drains directly into the cavernous sinus or adjacent dural vein ${ }^{(5,6)}$.

They usually occurs in middle-aged or postmenopausal women, but can occur in any gender or any age ${ }^{(7)}$.

The spontaneous fistulas account for approximately $25 \%$ of cases, but the traumatic cause is the most prevalent one ${ }^{(1-7)}$. The pathogenesis of spontaneous fistulas is controversial; it is believed that the dural fistulas are formed after breaking the fragile wall of one or more dural arteries which normally come out through the cavernous sinus or which are carried out by an attempt to provide a collateral venous flow in response to spontaneous thrombosis of the veins present in the cavernous sinus ${ }^{(7)}$.

Most patients present high high $\operatorname{IOP}^{(5,7,9)}$. The mechanism involved in the elevation of IOP is well understood: it is due to the reversion of the arterial blood draining that promotes mixing between arterial and venous blood and leads to a reduction in blood pressure and increase in orbital venous pressure resulting in increased episcleral venous pressure, directly influencing the increased flow resistance of the aqueous humor in the trabecular mesh $\operatorname{area}^{(5-9)}$.
Patients may also present engorged episcleral and conjunctival veins, minimal proptosis and presence of ocular pulse or puff ${ }^{(8)}$. The presence and intensity of these symptoms are not only due to the size of the fistula, but is more directly related to the venous collateral circulation previously established, which can reduce the final charge in the ophthalmic veins ${ }^{(2)}$.

The closed-angle glaucoma was associated to arteriovenous fistulas ${ }^{(9)}$. It is believed that the high pressure in the vorticose veins leads to congestion and edema of the ciliary and choroid bodies, thus producing the anterior displacement of the irido-crystalline diaphragm and, ultimately, a shallower anterior chamber ${ }^{(9)}$.

In the literature, a successful closure of the fistula by embolization ranged from 58 to $100 \%{ }^{(10)}$. In this case, embolization was effective in the anatomical closure of the fistula and the reversion of the associated symptoms, except the resolution of the increased IOP, which may be explained in part by the development of closed-angle glaucoma by the presence of goniosynechia at $270^{\circ}(11)$.

\section{REFERENCES}

1. Keltner JL, Satterfield D, Dublin AB, Lee BCP. Dural and carotid cavernous sinus fistulas: diagnosis, management, and complications. Ophthalmology. 1987;94(12):1585-600. 
2. Henderson JW, Schneider RC. The ocular findings in carotidcavernous fistula in a series of 17 cases. Am J Ophthalmol. 1959;48:585-97.

3. Sanders MD, Hoyt WF. Hypoxic ocular sequelae of carotid-cavernous fistulae: study of the causes of visual failure before and after neurosurgical treatment in a series of 25 cases. Br J Ophthalmol. 1969;53(2):82-97.

4. Palestine AG, Younge BR, Piepgras DG. Visual prognosis in carotid-cavernous fistula. Arch Ophthalmol. 1981;99(9):1600-3.

5. Phelps CD, Thompson HS, Ossoinig KC. The diagnosis and prognosis of atypical carotid-cavernous fistula (red-eyed shunt syndrome). Am J Ophthalmol. 1982;93(4):423-36.

6. Grove Jr AS. The dural shunt syndrome. Pathophysiology and clinical course. Ophthalmology. 1984;91(1):31-44.

7. Grumann AJ, Boivin-Faure L, Chapot R, Adenis JP, Robert PY. Ophthalmologic outcome of direct and indirect carotid cavernous fistulas. Int Ophthalmol. 2012;32(2):153-9.

8. Allingham RR, Damji KF, Freedman S, Moroi SE, Shafranov G, Shields MB. Shields: tratado de glaucoma. 5a ed. Rio de Janeiro: Cultura Médica; 2008.
9. Ishijima K, Kashiwagi K, Nakano K, Shibuya T, Tsumura $\mathrm{T}$, Tsukahara S. Ocular manifestations and prognosis of secondary glaucoma in patients with carotid-cavernous fistula. Jpn JOphthalmol 2003;47(6):603-8.

10. Kac MJ, Kac SI, Martins AG. Glaucoma secundário à fístula carótido-cavernosa espontânea com resolução após a embolização da fístula: relato de caso. Arq Bras Oftalmol. 2010;73(4):370-2.

11. Talajic JC, Assalian A, Roy D, Harasymowycz PJ. Angle closure glaucoma after angiography of carotid-cavernous fistula - A case report. J Glaucoma 2010;19(1):73-4.

\section{Corresponding author:}

Rafael Aguiar Carvalho

Av. Getulio Guaritá 331- ZIP Code: 38025-440, Uberaba/MG.

Phone: (31) 9100-1111 FAX: (34) 3318-5584

E-mail: rafaelcarvalho86@gmail.com 